\title{
Glioblastoma in a Patient with Neurofibromatosis Type 1: A Case Report and Review of the Literature
}

\author{
Tae-Seok Jeong, Gi-Taek Yee \\ Department of Neurosurgery, Gil Medical Center, Gachon University, Incheon, Korea
}

Received August 8, 2013

Revised November 8, 2013

Accepted March 7, 2014

\section{Correspondence}

Gi-Taek Yee

Department of Neurosurgery,

Gil Medical Center, Gachon University,

21 Namdong-daero 774beon-gil,

Namdong-gu, Incheon 405-760, Korea

Tel: +82-32-460-3304

Fax: +82-32-460-3899

E-mail: gtyee@gilhospital.com

\begin{abstract}
Neurofibromatosis type 1 (NF1) is an autosomal dominantly inherited familial tumor syndrome. Benign tumors such as pilocytic astrocytoma, optic glioma make up the majority of intracranial neoplasms in patients with NF1. There have only been a handful of cases in which adult glioblastoma presented with NF1. A 32-year-old male presented with headache and radiological studies showing a high grade intraaxial tumor. The patient underwent gross total surgical excision and the pathology revealed glioblastoma. After the surgery, he received concomitant chemo-radiotherapy with temozolomide and adjuvant temozolomide chemotherapy. We report a NF1 patient who developed glioblastoma and reviewed related articles.
\end{abstract}

Key Words Glioblastoma; Neurofibromatosis type 1; CCRT; Temozolomide.

\section{INTRODUCTION}

Neurofibromatosis type 1 (NF1) is an autosomal dominantly inherited familial tumor syndrome. The incidence of NF1 is about 1 in 3500 individuals [1]. Benign brain tumors such as pilocytic astrocytomas, optic-hypothalamic gliomas are the majority of intracranial neoplasms found in patient with NF1. However, there is an increased risk of developing malignant tumors in the central and peripheral nervous system $[2,3]$. Glioblastoma is a common malignant brain tumor in adults but glioblastoma in patients with NF1 is rare. Huttner et al. [4] reported that children with NF1 may be at risk of glioblastoma and that the prognosis of glioblastoma in children with NF1 might be better than those without NF1. We present rare occurrence of glioblastoma with NF1 in a 32-yearold man and its treatment.

\section{CASE REPORT}

A 32-year-old man presented with progressive headache. His neurologic examination was normal. He had multiple

This is an Open Access article distributed under the terms of the Creative Commons Attribution Non-Commercial License (http://creativecommons.org/licenses/by-nc/3.0) which permits unrestricted non-commercial use, distribution, and reproduction in any medium, provided the original work is properly cited. soft masses on his body including the scalp, and also had multiple café-au-lait spots over his chest, abdomen, back, and arms. The patient had no family history of neurofibromatosis. The magnetic resonance imaging (MRI) showed a huge well enhancing mass with peri-tumoral edema in the right frontal lobe and the apparent diffusion coefficient maps demonstrated iso or slightly low signal intensity compared to the brain parenchyme (Fig. 1). The patient underwent a right frontal craniotomy and gross total tumor removal was performed. We removed some of the scalp masses as we made the scalp incision for the craniotomy. The pathological examination of the intracranial and scalp mass revealed glioblastoma and plexiform neurofibroma respectively (Fig. 2). On immunohistochemistry, the intracranial specimen was strongly positive for glial fibrillary acidic protein (GFAP), and negative for epidermal growth factor receptor (EGFR). The proliferation marker Ki-67 was $10 \%$ and the methylguanine methyltransferase (MGMT) gene was unmethylated on methylation-specific polymerase chain reaction. The patient underwent standard concomitant chemo-radiotherapy followed by adjuvant chemotherapy with temozolomide. After finishing 6-cycles of adjuvant chemotherapy, the patient showed no remarkable symptoms and follow-up MRI obtained 9 months after surgery showed no evidence of recurrence (Fig. 3). 


\section{DISCUSSION}

NF1, also known as von Recklinghausen disease, is char- acterized by multiple skin lesions (café-au-lait spots, axillary and/or inguinal freckling), Lisch nodules, and various tumors including optic glioma, brain tumors, soft-tissue sarco-
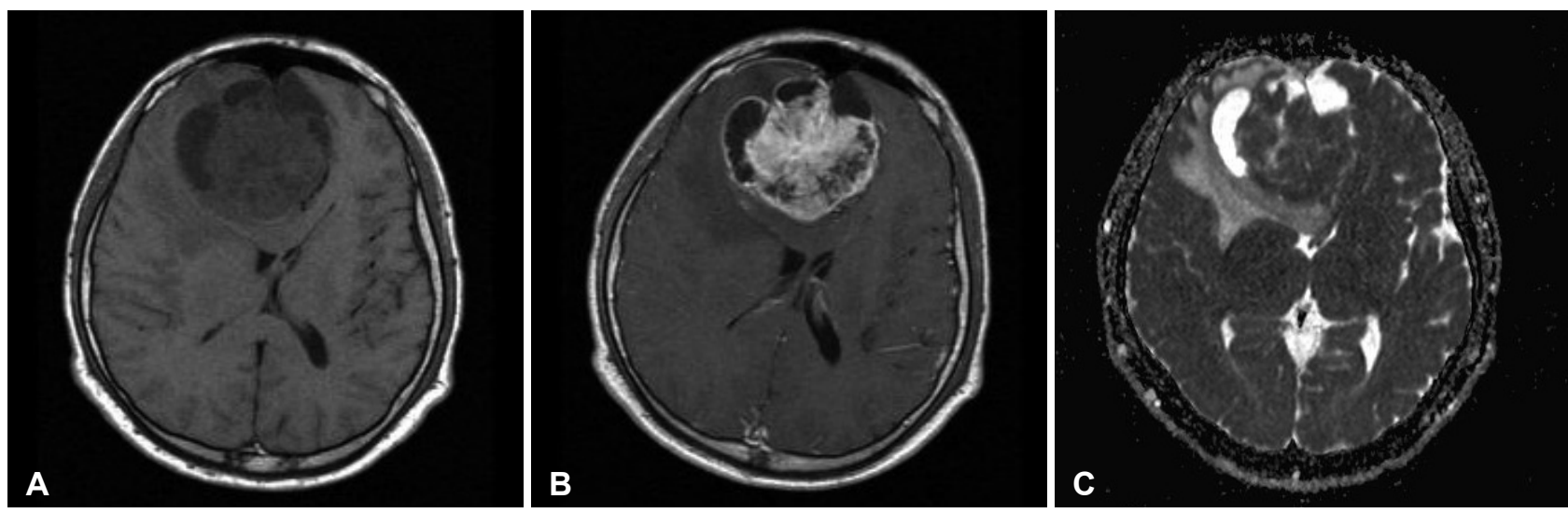

Fig. 1. Preoperative magnetic resonance imaging (MRI) reveals large mass in the frontal lobe cross the midline and compress both frontal horns of ventricle. A: T1-weighted image shows large tumor with peripheral cyst component. B: Gd-contrast enhanced MRI shows well enhancement. C: Apparent diffusion coefficient maps demonstrates iso or slight low signal intensity.
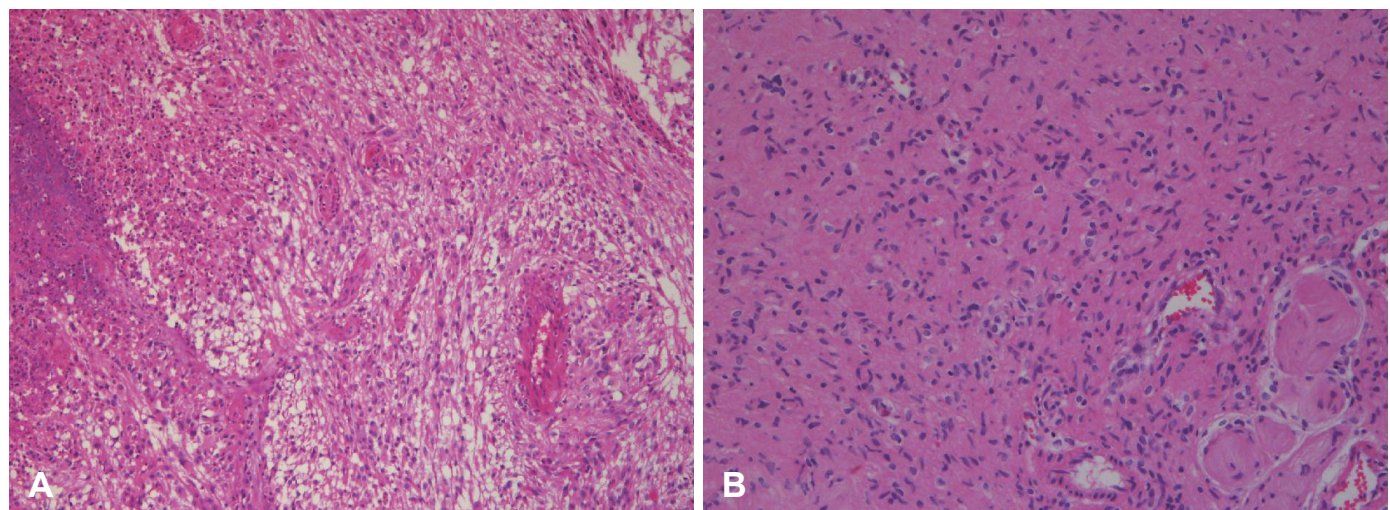

Fig. 2. Histologic examination. A: H\&E stain $(\times 100)$ shows characteristic features of glioblastoma. B: Scalp mass is revealed plexiform neurofibroma (H\&E stain, $\times 200)$.
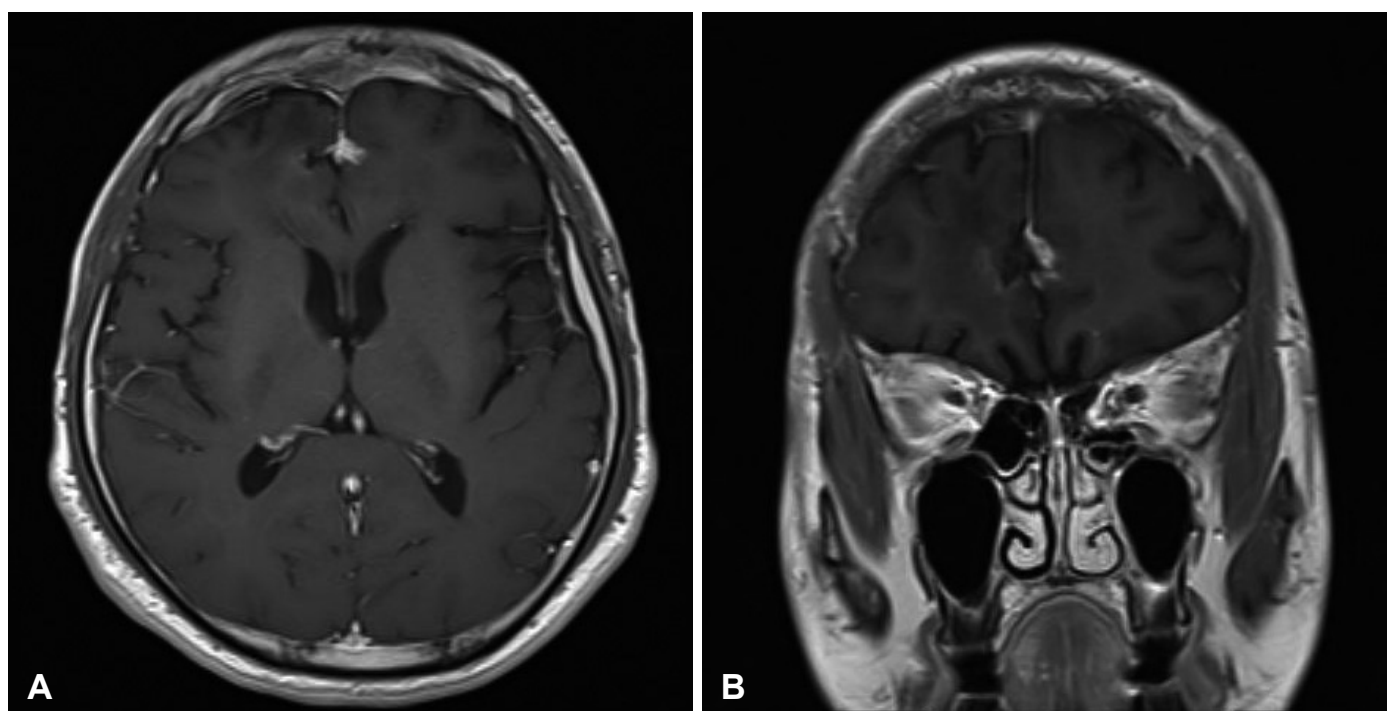

Fig. 3. Post-adjuvant chemotherapy with temozolomide, 9 months after surgery. Gd-enhanced axial (A) and coronal (B) T1-weighted MR images reveal no evidence of tumor recurrence. 
Table 1. The characteristics of previous cases of Glioblastoma with NF1 in adults

\begin{tabular}{|c|c|c|c|c|c|}
\hline Authors & Reference year & Age (years)/sex & Location & Treatment & Post-treatment course \\
\hline Pál et al. [8] & 2001 & $37 /$ female & Occipital & & No treatment \\
\hline Mehta et al. [9] & 2008 & $63 /$ male & Parietal & $\begin{array}{l}\text { Bx only } \\
\text { Refuse any intervention }\end{array}$ & $\begin{array}{l}\text { Dead } 2 \text { months after } \\
\text { his initial presentation }\end{array}$ \\
\hline Hakan and Aker [10] & 2008 & 28/female & Frontal & $\begin{array}{l}\text { SR+RT+CTx } \\
\text { (temozolomide) }\end{array}$ & Dead 41 months after surgery \\
\hline Broekman et al. [11] & 2009 & 28/female & Cerebellum & $\mathrm{SR}+\mathrm{RT}+\mathrm{CTx}$ & Dead 6 months after surgery \\
\hline Present case & & $32 / \mathrm{male}$ & Frontal & $\mathrm{SR}+\mathrm{RT}+\mathrm{CTx}$ & Alive \\
\hline
\end{tabular}

Bx: biopsy, SR: surgical resection, RT: radiation therapy, CTx: chemotherapy, NF1: neurofibromatosis type 1

mas, carcinomas (breast, lungs, gastrointestinal tract, thyroid, pharynx, ovaries), malignant melanoma, pheochromocytomas [5-7]. The majority of intracranial tumors with NF1 are pilocytic astrocytomas and optic gliomas which are thought to be pathologically low grade. Up to the year 2010, 12 patients with NF1 associated with glioblastoma had been reported [4]. Among them four occurred in adults. One patient was clinically represented with progressive multiple sclerosis and neurofibromatosis but glioblastoma remained silent during the patient's life. The pathology of glioblastoma was revealed by autopsy [8]. Table 1 shows the characteristics of the glioblastomas with NF1 in adults [8-11]. Huttner et al. [4] reviewed five glioblastoma patients in children with NF1 and reported their clinicopathologic features. This study suggested that pathological features such as increased $p 53$ expression, increased EGFR amplification, and increased proliferative indices might have predicted a worse overall outcome. They also provided that the survival of glioblastoma patient with NF1 was better than those without NF1. The median overall survival of patients with and without NF1 was 9.25 and 1.08 years respectively. However, because of the limited number of patients, further investigation is needed. In adults, glioblastoma is the most common and aggressive primary brain tumor. The methylation status of the MGMT gene promoter is currently a promising molecular prognostic marker. There is a significant association between MGMT promoter methylation and the outcome of glioblastoma patients treated with temozolomide. Molecular analysis of glioblastomas arising in NF1 patients showed the presence of genetic alterations such as p16INK4A/ARF deletion and $p 53$ mutations [12]. Some studies have reported the cooperation of mutations in NF1 and p53 in the development astrocytomas in transgenic mice $[13,14]$. In our case, the promoter methylation of MGMT gene was not observed. Immunohistochemical findings were positive for GFAP, and negative for EGFR. Preliminary studies reported that the prognosis of glioblastoma with NF1 in children may differ from patient without NF1 [4]. In adults, there is limited information about glioblastoma with NF1 cases. In this present case, the patient was treated using surgical excision and chemoradiotherapy with temozolomide. Further investigation for the glioblastoma patients with NF1 in adults would be necessary.

\section{Conflicts of Interest}

The authors have no financial conflicts of interest.

\section{REFERENCES}

1. Friedman JM. Epidemiology of neurofibromatosis type 1. Am J Med Genet 1999;89:1-6.

2. Blatt J, Jaffe R, Deutsch M, Adkins JC. Neurofibromatosis and childhood tumors. Cancer 1986;57:1225-9.

3. Korf BR. Malignancy in neurofibromatosis type 1. Oncologist 2000; 5:477-85.

4. Huttner AJ, Kieran MW, Yao X, et al. Clinicopathologic study of glioblastoma in children with neurofibromatosis type 1. Pediatr Blood Cancer 2010;54:890-6.

5. Farmer JP, Khan S, Khan A, et al. Neurofibromatosis type 1 and the pediatric neurosurgeon: a 20 -year institutional review. Pediatr Neurosurg 2002;37:122-36.

6. Guillamo JS, Créange A, Kalifa C, et al. Prognostic factors of CNS tumours in Neurofibromatosis 1 (NF1): a retrospective study of 104 patients. Brain 2003;126(Pt 1):152-60.

7. Walther MM, Herring J, Enquist E, Keiser HR, Linehan WM. von Recklinghausen's disease and pheochromocytomas. J Urol 1999;162: 1582-6.

8. Pál E, Gömöri E E, Gáti I. Neurofibromatosis and glioblastoma in a case of multiple sclerosis. Eur J Neurol 2001;8:717-8.

9. Mehta RS, Abraham M, Plesa C, Ennis P. Glioblastoma multiforme in an adult with von Recklinghusen disease. Commun Oncol 2008;5:544-8.

10. Hakan T, Aker FV. Case report on a patient with neurofibromatosis type 1 and a frontal cystic glioblastoma. Neurol Neurochir Pol 2008; 42:362-5.

11. Broekman ML, Risselada R, Engelen-Lee J, Spliet WG, Verweij BH. Glioblastoma multiforme in the posterior cranial fossa in a patient with neurofibromatosis type I. Case Rep Med 2009;2009:757898.

12. Gutmann DH, James CD, Poyhonen M, et al. Molecular analysis of astrocytomas presenting after age 10 in individuals with NF1. Neurology 2003;61:1397-400.

13. Reilly KM, Loisel DA, Bronson RT, McLaughlin ME, Jacks T. Nf1; Trp53 mutant mice develop glioblastoma with evidence of strain-specific effects. Nat Genet 2000;26:109-13.

14. Zhu Y, Guignard F, Zhao D, et al. Early inactivation of p53 tumor suppressor gene cooperating with NF1 loss induces malignant astrocytoma. Cancer Cell 2005;8:119-30. 